\title{
In vivo functional flowmetric behavior of the radial artery graft: Is the composite Y-graft configuration advantageous over conventional aorta-coronary bypass?
}

Francesco Onorati, MD, ${ }^{\mathrm{a}}$ Antonino Salvatore Rubino, MD, ${ }^{\mathrm{a}}$ Lucia Cristodoro, MD, ${ }^{\mathrm{a}}$ Cristian Scalas, MD, Sergio Nucera, MD, ${ }^{\mathrm{a}}$ Francesco Santini, MD, ${ }^{\mathrm{b}}$ and Attilio Renzulli, MD, PhD, FETCS ${ }^{\mathrm{a}}$

Introduction: Intraoperative flowmetric results of different configurations (Y-graft or aorta-coronary) of radial artery grafts have been poorly investigated.

\begin{abstract}
Methods: We report the results of an observational study designed to analyze transit-time flow measurements at baseline and during 1:1 intra-aortic balloon pumping in 114 consecutive patients receiving the radial artery as a aorta-coronary bypass (group A, 72 patients) or as a Y-graft with the left internal thoracic artery (group B, 42 patients). Graft flow reserve, recruited by 1:1 intra-aortic balloon pumping) greater than 1 indicated recruitment of surplus graft flow. Results were stratified by grafted territory and surgical technique.
\end{abstract}

Results: Hospital outcome was comparable. Baseline transit-time flow results were similar between the 2 groups in terms of maximum diastolic flow, minimum systolic flow, mean flow, and pulsatility index. Graft flow reserve was not recruited by intra-aortic balloon pumping in $3(2.7 \%)$ malfunctioning single aorta-oronary radial artery bypass grafts $(P=.005$ versus successful radial artery bypass grafts). Graft flow reserve was recruited $(>1)$ by intra-aortic balloon pumping in the remaining 111 patent radial artery bypass grafts. Y-grafts showed higher maximum diastolic flow $P<.0001)$, mean flow $(P<.0001)$, graft flow reserve $(P<.0001)$, percentage improvement of maximum diastolic flow $(P<.0001)$, and of mean flow $(P<.0001)$ compared with aorta-coronary radial artery bypass grafts. These results were confirmed for the right coronary $(P \leq .004)$ and the circumflex territory $(P \leq$ $.001)$, for off-pump $(P \leq .008)$ or cardiopulmonary bypass $(P<.0001)$ and for patients undergoing isolated bypass grafting $(P<.0001)$.

Conclusions: Intraoperative flows of radial artery bypass grafts showed comparable baseline results in single aorta-coronary conduits and Y-grafts. Graft flow reserve recruited by intra-aortic balloon pumping was higher in Y-conduits, regardless of the grafted territory and the perfusion strategy chosen. Failed radial artery bypass grafts did not improve transit-time flow results during 1:1 intra-aortic balloong pumping nor showed any recruitment of graft flow reserve. (J Thorac Cardiovasc Surg 2010;140:292-7)

Supplemental material is available online.

Earn CME credits at

http://cme.ctsnetjournals.org

The recent demonstration of improved survival in patients undergoing arterial revascularization stimulated surgeons to an increasing use of arterial grafts other than internal thoracic arteries (ITAs) to completely revascularize the heart. ${ }^{1}$

From the Cardiac Surgery Unit, Magna Graecia University of Catanzaro, Catanzaro, Italy, ${ }^{\mathrm{a}}$ and the Cardiac Surgery Unit, University of Verona, Verona, Italy. ${ }^{\mathrm{b}}$ Disclosures: None.

Received for publication June 16, 2009; revisions received Sept 22, 2009; accepted for publication Oct 22, 2009; available ahead of print Dec 28, 2009.

Address for reprints: Francesco Onorati, MD, Cardiac Surgery Unit, Magna Graecia University, Catanzaro, Italy (E-mail: frankono@libero.it).

$0022-5223 / \$ 36.00$

Copyright (c) 2010 by The American Association for Thoracic Surgery doi:10.1016/j.jtcvs.2009.10.028
In this setting, the radial artery (RA) is the most frequently used arterial conduit worldwide. ${ }^{1}$ Different configurations of RAs as conduits for myocardial revascularization have been reported. ${ }^{2}$ However, despite comparable clinical outcomes, few studies have addressed the in vivo functional flowmetric behavior of different surgical configurations. ${ }^{2}$ In particular, the recent availability of transit-time flowmetry (TTF) has allowed surgeons to explore in vivo the functional behavior of different conduits. ${ }^{3,4}$ Moreover, the correlation between TTF results and graft patency at short-term angiographic follow-up has popularized the use of TTF technology in daily practice. ${ }^{4}$

Furthermore, despite previous concerns that have arisen toward the appropriateness of a single blood supply through other arterial conduits in composite configurations, it has been clearly demonstrated that the main stem of an ITA supplies sufficient blood in composite Y- or T-graft configurations. ${ }^{5}$ However, the literature lacks studies reporting the in vivo amount of blood flowing through the 2 different branches of composite grafts with RAs. Moreover, although comparable blood flow has been reported in composite grafts 

Abbreviations and Acronyms
$\mathrm{CABG}=$ coronary artery bypass graft
$\mathrm{CPB}=$ cardiopulmonary bypass
GRF $\quad=$ graft flow reserve
IABP $=$ intra-aortic balloon pump
ITA $=$ internal thoracic artery
$\mathrm{LAD}=$ left anterior descending coronary artery
LITA $=$ left internal thoracic artery
$\mathrm{OPCABG}=$ off-pump coronary artery bypass grafting
PI = pulsatility index
RA $\quad=$ radial artery
TTF $\quad=$ transit-time flowmetry

using either double ITAs or ITA-RAs, ${ }^{5,6}$ to the best of our knowledge no literature data have ever addressed differences in flowmetric results of the RA in coronary artery bypass grafting $(\mathrm{CABG})$ when used as single aorta-coronary conduits or as composite Y-grafts; similarly, no stratification of TTF results based on the grafted territory and the surgical technique used (off-pump/on-pump) has ever been reported.

Therefore, the aim of the present observational study was to investigate TTF results of RA CABGs in 2 different configurations (single aorta-coronary [(group A] or composite Y-graft with left ITA [LITA; group B], in different target territories, either off-pump (OPCABG) or on cardiopulmonary bypass $(\mathrm{CPB})$, during a 16 -month period at a single academic institution.

\section{PATIENTS AND METHODS \\ Patients}

We analyzed data from 114 consecutive patients undergoing $\mathrm{CABG}$ with preoperative intra-aortic balloon pump (IABP) support at our institution during the past 16 months (January 2008-May 2009). Seventy-two patients (group A) underwent aorta-coronary RA CABG, the remaining 42 (group B) underwent composite Y-graft with RA and LITA. All patients received preoperative IABP, according to institutional policy. ${ }^{4}$ The study protocol was approved by the institution's ethical committee/institutional review board, and informed consent was obtained from each patient.

\section{Surgical Technique}

To better support hemodynamic function before CABG, institutional policy called for percutaneous insertion of an IABP with the technique already described. ${ }^{4}$ Surgery was performed through a median sternotomy by the same surgeons (A.R., F.O.). Harvesting of the LITA and RA has been standardized and already reported in the literature. ${ }^{3}$ In brief, the composite LITA-RA anastomoses were performed in advance, after systemic heparinization. The RA was spatulated $2 \mathrm{~mm}$ and anastomosed to a 4- to 5-mm incision in the pleural aspect of the LITA at the level where the LITA enters the pericardial space anterior to the left atrial appendage. Obtuse marginal branches and the right coronary territory were the targets of RA grafts. Distal anastomoses were performed with 8-0 polypropylene stitches. Intravenous or oral vasodilators, except for enoximone infusion, were never used after RA grafting. So that the risk for "string sign" and/or competitive flow from the native coronary circulation could be avoided, RA grafting was only accomplished on target vessels with more than $80 \%$ stenosis at least. The choice for aorta-coronary conduit configuration or for the Y-configuration was left to surgeon's choice, except in $4(3.5 \%)$ patients with diffuse calcifications of the ascending aorta and $1(0.8 \%)$ patient with "egg-shell" aorta, in whom composite Y-grafting was considered mandatory. Proximal anastomoses of all RA grafts were directly done on the ascending aorta. The use of CPB and OPCABG protocols was standardized. ${ }^{3}$ Both surgeons were able to perform either traditional or Y-conduit grafts.

\section{Flowmetric Analysis and Evaluation of Graft Flow Reserve}

Graft flowmetry was evaluated during IABP support and during its temporary cessation to avoid intraoperative bias and to standardize the technique. Thus patients served as their own controls. Graft function was assessed under stable hemodynamic conditions, generally 30 minutes after protamine administration. Considering that graft flow reserve (GFR) is also influenced by loading conditions, TTF analysis was performed under similar volume loading (central venous pressure: group A $9.7 \pm 2.4 \mathrm{~mm} \mathrm{Hg}$ vs group B $10.2 \pm 1.9 \mathrm{~mm} \mathrm{Hg} ; P=.689)$. Flowmetry of the grafts was performed with a transit-time flowmeter (HT313 Transonic; Transonic Systems Inc, Ithaca, NY). Different probe sizes $(2,2.5$, or $3 \mathrm{~mm}$ ) were available to avoid distortion or compression of grafts. Skeletonization of a small segment of the proximal RA branch and of the proximal LITA branch was necessary to reduce the quantity of tissue interposed between the vessel and the probe.

The curves were always coupled with the electrocardiogram tracing to differentiate systolic from diastolic flow. The following variables were calculated-maximum diastolic, minimum systolic, and mean flows (expressed in $\mathrm{mL} / \mathrm{min}$ ) — directly derived from the flowmeter, and pulsatility index (PI, derived from maximum diastolic flow - minimum systolic flow/ mean flow). The flow pattern (systolic, diastolic) was directly derived from the flow curve of the trace. Data from LITA and RA conduits, stratified by grafted territory (circumflex and right coronary) and surgical technique (OPCABG/CPB) were recorded. So that the potential of IABP to recruit GFR could be evaluated, TTF measurements were recorded both during 1:1 IABP support and after 5 minutes of temporary cessation ("IABP off''). Systolic, end-diastolic, and mean arterial pressures were recorded invasively through a pressure transducer connected to the RA and compared during 1:1 IABP support and during its temporary cessation. Percent improvements in maximum diastolic, minimum systolic, and mean blood flows were calculated. The GFR was calculated from the mean flow occurring during 1:1 IABP support divided by the mean flow during temporary cessation, as already reported. ${ }^{3}$

\section{Data Collection}

According to an institutional policy, inotropes were started immediately either in on-pump CABG or in OPCABG, starting with enoximone at a dosage of $5 \mu \mathrm{g} \cdot \mathrm{kg}^{-1} \cdot \mathrm{min}^{-1}$ in respect with the protocol already reported. ${ }^{7}$ Troponin I from the peripheral venous line was collected preoperatively and on the first and second postoperative days.

Hospital mortality and morbidity were defined as previously reported. ${ }^{3,7}$

\section{Statistical Analysis}

All data were prospectively recorded by means of the institutional database. Statistical analysis was performed with use of the SPSS program for Windows, version 13.0 (SPSS Inc, Chicago, Ill). Continuous variables are presented as means \pm standard deviation, and categorical variables are presented as number (percentage) of patients. Data were checked for normality before analysis. The paired-sample $t$ test was used to evaluate differences in continuous variables during 1:1 IABP support versus during its temporary cessation ("IABP-off"). One-way analysis of variance was used to evaluate the significance of differences among types of bypass grafts. Two-way analysis of variance for repeated measures was used for comparisons within (1:1 
TABLE 1. TTF results during 1:1 IABP and during temporary IABP discontinuation, by type of bypass graft

\begin{tabular}{|c|c|c|c|c|}
\hline & IABP D/C & 1:1 IABP & $\boldsymbol{P} \dagger$ & $\boldsymbol{P} \ddagger$ \\
\hline \multicolumn{5}{|l|}{ RA CABGs } \\
\hline \multicolumn{5}{|l|}{ Maximum diastolic flow } \\
\hline Group A (69 patients) & $67.9 \pm 16.9$ & $86.7 \pm 25.2$ & .0001 & .0001 \\
\hline Group B (42 patients) & $67.4 \pm 11.4$ & $136.5 \pm 25.4$ & .0001 & \\
\hline$P^{*}$ & .284 & .0001 & - & \\
\hline \multicolumn{5}{|l|}{ Mean flow } \\
\hline Group A (69 patients) & $35.9 \pm 10.9$ & $48.9 \pm 15.2$ & .0001 & .0001 \\
\hline Group B (42 patients) & $36.5 \pm 9.5$ & $72.7 \pm 19.9$ & .0001 & \\
\hline$P^{*}$ & .709 & .0001 & - & \\
\hline \multicolumn{5}{|l|}{ Minimum systolic flow } \\
\hline Group A (69 patients) & $9.8 \pm 7.0$ & $8.6 \pm 7.8$ & .445 & .206 \\
\hline Group B (42 patients) & $10.9 \pm 8.3$ & $9.9 \pm 8.0$ & .473 & \\
\hline$P^{*}$ & .285 & .025 & - & \\
\hline \multicolumn{5}{|l|}{ Pulsatility index } \\
\hline Group A (69 patients) & $2.3 \pm 1.0$ & $3.0 \pm 0.8$ & .0001 & .863 \\
\hline Group B (42 patients) & $1.8 \pm 0.5$ & $3.5 \pm 0.5$ & .0001 & \\
\hline$P^{*}$ & .065 & .0001 & - & \\
\hline \multicolumn{5}{|l|}{ LITA-LAD } \\
\hline \multicolumn{5}{|l|}{ Maximum diastolic flow } \\
\hline Group A (69 patients) & $68.9 \pm 32.3$ & $128.2 \pm 50.6$ & .0001 & .885 \\
\hline Group B (42 patients) & $66.8 \pm 35.2$ & $125.3 \pm 55.8$ & .0001 & \\
\hline$P^{*}$ & .986 & .869 & - & \\
\hline \multicolumn{5}{|l|}{ Mean flow } \\
\hline Group A (69 patients) & $34.1 \pm 21.4$ & $57.0 \pm 31.1$ & .0001 & .848 \\
\hline Group B (42 patients) & $32.9 \pm 25.6$ & $57.2 \pm 34.8$ & .0001 & \\
\hline$P^{*}$ & .967 & .973 & - & \\
\hline \multicolumn{5}{|l|}{ Minimum systolic flow } \\
\hline Group A (69 patients) & $6.8 \pm 0.4$ & $7.9 \pm 1.0$ & .328 & .967 \\
\hline Group B (42 patients) & $6.5 \pm 0.6$ & $8.1 \pm 1.1$ & .299 & \\
\hline$P^{*}$ & .945 & .831 & - & \\
\hline \multicolumn{5}{|l|}{ Pulsatility index } \\
\hline Group A (69 patients) & $2.2 \pm 0.5$ & $3.4 \pm 1.2$ & .0001 & .909 \\
\hline Group B (42 patients) & $2.1 \pm 0.4$ & $3.5 \pm 0.8$ & .0001 & \\
\hline$P^{*}$ & .896 & .946 & - & \\
\hline
\end{tabular}

$T T F$, Transit-time flowmetry; $I A B P$, intra-aortic balloon pump; $D / C$, discontinued; $R A$, radial artery; $C A B G$, coronary artery bypass graft; $L I T A$, left internal thoracic artery; $L A D$, left anterior descending. $* P$ value for the comparison of flows at baseline and

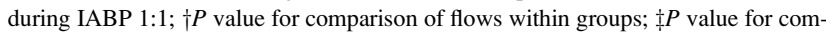
parison of flows between groups.

IABP versus "IABP-off”') and between groups (group A vs group B, normal-functioning versus failed grafts). Categorical variables were analyzed with the use of either the $\chi^{2}$ test or Fisher's exact test.

\section{RESULTS \\ Hospital Outcome}

The 2 groups proved homogeneous for preoperative variables (Table E1). Similarly, no differences were recorded for intraoperative variables (Table E1) or for perioperative troponin I leakage and for the need for perioperative inotropic support (Table E2). Three (2.6\%) patients died during hospitalization, because of perioperative acute myocardial infarction $(\mathrm{n}=1)$, stroke $(\mathrm{n}=1)$, and multiorgan failure after pneumonia $(\mathrm{n}=1)$. However, no differences were de- tected in hospital mortality between the 2 groups (group A: $2 / 72$ [2.8\%] vs group B $1 / 42$ [2.4\%]; $P=.694)$. Similarly, the 2 groups were comparable for postoperative complication rate (perioperative acute myocardial infarction group A/group B $0 / 1 ; P=.368$; low output syndrome group A/ group $\mathrm{B} 0 / 1 ; P=.368$; acute renal failure group $\mathrm{A} /$ group B $2 / 1 ; P=.694$; acute respiratory failure group A/group B $8 / 4 ; P=.529 ;$ stroke group $\mathrm{A} /$ group $\mathrm{B} 1 / 1 ; P=.603$ ), giving a global morbidity rate of $13.9 \%$ in group A versus $11.9 \%$ in group $\mathrm{B}(P=.502)$. Finally, there were neither major nor minor IABP-related complications during the study period.

\section{TTF Analysis and GFR}

There were 3 cases of failed CABG (all of them were aorta-coronary grafts), one of which was responsible for perioperative myocardial infarction (Table 1). Among these grafts, the maximum diastolic, minimum systolic, and the mean blood flow rates were significantly lower than those among normally functioning grafts. Moreover, the failed grafts did not show improvement of blood flow during 1:1 IABP and a corresponding lack of GFR. In all these patients, the detection of poor TTF findings was associated with corresponding ischemic electrocardiographic and/or echocardiographic signs (new akinetic or hypokinetic segments) of the corresponding myocardial territories. Two patients of these 3 cases of failed CABG had good distal vessel quality at preoperative coronary angiography that could not explain the unsatisfactory poor TTF results. Therefore, in these 2 cases, the distal anastomoses have been redone. However, to avoid intraoperative bias, these 3 cases were excluded from the study.

Therefore, the results reported describe the TTF analysis performed on 111 functioning grafts (group $\mathrm{A}=69$ patients; group $B=42$ patients). When TTF results were analyzed during temporary IABP cessation ("baseline" values), no differences were recorded between the 2 groups in terms of maximum diastolic flow, minimum systolic flow, mean flow, and PI when the 2 different RA CABG configurations were tested (Table 1); similarly, no differences were recorded when the LITA-left anterior descending (LAD) graft was tested under baseline condition. However, maximum diastolic flow, mean flow, and PI significantly improved during IABP assistance in LITA-LAD and in the 2 different RA CABG constructions, although such increment of flow was significantly higher in Y-graft configuration than in single aorta-coronary configuration for RA CABGs (Table 1). However, no difference in LITA-LAD flow was detected between the 2 groups when 1:1 IABP assistance was employed (Table 1). GFR was recruited (>1) during 1:1 IABP in all 111 normally functioning RA grafts, although significantly higher GFR was noted in Y-RA CABG compared with single aorta-coronary CABG (Table 2). Similar results were evidenced when percent improvements of maximum diastolic flow and of mean flow were computed (Table 2). 
TABLE 2. GFR and percent improvement of maximum diastolic and mean flows by type of bypass graft

\begin{tabular}{lccc}
\hline \multicolumn{1}{c}{ Variables } & $\begin{array}{c}\text { Group A } \\
\text { (69 patients) }\end{array}$ & $\begin{array}{c}\text { Group B } \\
\mathbf{( 4 2} \text { patients })\end{array}$ & $\boldsymbol{P}$ \\
\hline GFR & $1.37 \pm 0.15$ & $1.99 \pm 0.18$ & .0001 \\
Maximum & $27.8 \%$ & $102.6 \%$ & .0001 \\
$\quad$ diastolic flow & $(7.3 \%-62.0 \%)$ & $(57.7 \%-155.2 \%)$ & \\
$\quad$ improvement, $\%$ & & & \\
$\quad(95 \% \mathrm{CI})$ & & & \\
Mean flow & & $99.2 \%$ & .0001 \\
$\quad$ improvement, $\%$ & $(14.8 \%-89.4 \%)$ & $(43.9 \%-121.6 \%)$ & \\
$\quad(95 \%$ CI) & & & \\
\hline$G F R$, Graft flow reserve; $C I$, confidence interval. & &
\end{tabular}

Moreover, even though TTF analysis was accomplished at the same systolic arterial pressures during either 1:1 IABP or IABP cessation $(108.5 \pm 28.4 \mathrm{~mm} \mathrm{Hg}$ and $107.7 \pm 24.3 \mathrm{~mm}$ $\mathrm{Hg}$, respectively; $P=.314$ ), the maximum diastolic and mean flows on TTF analysis were higher during 1:1 IABP support versus IABP cessation, regardless of the presence of statistically significant lower end-diastolic and mean arterial pressures (end-diastolic pressure during TTF, $60.5 \pm$ $22.2 \mathrm{~mm} \mathrm{Hg}$ during 1:1 IABP vs $67.9 \pm 20.2 \mathrm{~mm} \mathrm{Hg}$ during IABP cessation; $P<.001$; mean arterial pressure during TTF, $70.9 \pm 10.3 \mathrm{~mm} \mathrm{Hg}$ during 1:1 IABP vs $83.2 \pm 9.9$ $\mathrm{mm} \mathrm{Hg}$ during IABP cessation; $P<.001$ ). However, no differences were recorded in the 2 groups when systolic, end-diastolic, and mean arterial pressures were considered during both 1:1 IABP and its cessation (systolic arterial pressure $P=.772$; end-diastolic arterial pressure $P=.698$; mean arterial pressure $P=.611$ ).

When TTF results of RA CABGs were further stratified for the perfusion strategy ("off-pump" or "on-pump," Table E3) or grafted territory (circumflex or right coronary territory, Table E4), a significantly higher maximum diastolic flow, mean flow, and GFR during 1:1 IABP were confirmed whenever Y-graft construction was preferred to single aorta-coronary RA grafts.

These results were also confirmed, either in terms of flowmetry or in terms of GFR, when patients with associated procedures were excluded from the analysis (Table 3 ).

\section{DISCUSSION}

Exclusive use of arterial conduits to achieve coronary revascularization is a potential solution for the late failure of saphenous vein grafts. ${ }^{2,8}$ Since the reintroduction of the RA in daily surgical practice, ${ }^{9}$ several studies have demonstrated the safety and effectiveness of RA CABG as the second conduit after ITAs. ${ }^{1,2}$ In the quest to perform routine total arterial revascularization, composite Y-graft methods are gaining popularity. ${ }^{2,8}$ However, whether the LITA is sufficient or not to provide adequate blood flow to all grafted territories is still debated. ${ }^{8}$ Even though some reports proved the effectiveness of composite arterial conduits, ${ }^{5}$ few studies ad-
TABLE 3. TTF results during 1:1 IABP and during temporary IABP discontinuation, excluding patients undergoing procedures other than myocardial revascularization

\begin{tabular}{lcccr}
\hline & IABP D/C & $\mathbf{1 : 1}$ IABP & $\boldsymbol{P} \dagger$ & $\boldsymbol{P}_{\dagger}^{\dagger}$ \\
\hline RA CABGs & & & & \\
Maximum diastolic flow & & & & \\
Group A (35 patients) & $68.6 \pm 12.2$ & $84.1 \pm 14.4$ & .0001 & .0001 \\
Group B (21 patients) & $70.6 \pm 9.9$ & $141.3 \pm 23.1$ & .0001 & \\
$P^{*}$ & .234 & .0001 & - & \\
Mean flow & & & & \\
Group A (35 patients) & $36.7 \pm 8.1$ & $47.7 \pm 9.8$ & .0001 & .0001 \\
Group B (21 patients) & $37.5 \pm 8.0$ & $74.1 \pm 17.1$ & .0001 & \\
$P^{*}$ & .366 & .0001 & - & \\
Minimum systolic flow & & & & \\
Group A (35 patients) & $8.5 \pm 6.6$ & $13.3 \pm 9.2$ & .0001 & .079 \\
Group B (21 patients) & $9.0 \pm 6.9$ & $21.4 \pm 13.6$ & .0001 & \\
$P^{*}$ & .688 & .0005 & - & \\
Pulsatility index & & & & \\
Group A (35 patients) & $1.8 \pm 0.6$ & $2.7 \pm 0.6$ & .0001 & .047 \\
Group B (21 patients) & $1.7 \pm 0.6$ & $3.4 \pm 0.6$ & .0001 & \\
$P^{*}$ & .505 & .0001 & - & \\
GFR & & & & \\
Group A (35 patients) & $1.3 \pm 0.1$ & .0001 & & \\
Group B (21 patients) & $2.0 \pm 0.2$ & & & \\
\hline
\end{tabular}

$T T F$, Transit-time flowmetry; $I A B P$, intra-aortic balloon pump; $D / C$, discontinued; $R A$ radial artery; $C A B G$, coronary artery bypass graft; $G F R$, graft flow reserve. ${ }^{*} P$ value for the comparison of flows at baseline and during IABP $1: 1 ; \nmid P$ value for comparison of flows within groups; $\ddagger P$ value for comparison of flows between groups.

dressed the functional in vivo behavior of these conduits. Furthermore, no studies compared flowmetric results of composite Y-grafts with those of single aorta-coronary conduits, nor did they evaluate the GFR of these 2 surgical techniques. TTF technology gave the possibility to investigate the functional behavior of $\mathrm{CABG}$, as well as to anticipate the angiographic patency. ${ }^{4,10,11}$ Accordingly, our group has recently demonstrated the ability of TTF measurements to investigate, during 1:1 IABP, the GFR of different conduits. ${ }^{3}$

Our results confirmed previous findings proving the appropriateness of blood supply with the composite configuration. Baseline maximum diastolic flow, mean flow, minimum systolic flow, and PI were comparable with either aorta-coronary or Y-configuration (Tables 1 to 3 and E1 to E3). Furthermore, the composite configuration did not affect the graft flow of the LITA limb, as demonstrated by the similar TTF findings. These data confirm those of Affleck and coworkers, ${ }^{6}$ showing excellent graft flow of composite LITA-RA T-grafts.

According to the institutional policy to use RA only on severely diseased ( $>80 \%$ stenosis) coronary arteries, our data are in line with those of Markwirth and associates, ${ }^{12}$ showing higher Y-conduit flows in cases of severe stenosis of the grafted coronary artery, and of Desai and coworkers, ${ }^{13}$ supporting the need for accurate choice of target vessels in cases of composite grafts. 
The main finding of our study is that Y-configuration is associated with higher GRF of RA limb compared with the isolated aorta-coronary configuration. Moreover, these data support the use of Y-conduits to assure higher coronary flow reserve. ${ }^{12}$

Our results could reflect the different biological properties of the SRA and LITA. He and $\mathrm{Liu}^{14}$ reported higher release of nitric oxide by the LITA compared with the RA. Moreover, the latter conduit exhibits greater contraction to chemical stimulation than does the LITA, ${ }^{15}$ and this higher vasoreactivity could affect the long-term graft patency. ${ }^{2,14,15}$

It could be speculated that the site of proximal anastomosis could influence graft function. In fact, in aorta-coronary RA CABG, the RA behavior relies totally on its biological properties. On the other hand, in Y-conduits, the LITA could modulate the side-branch conduit function. Accordingly, Tarr and coworkers ${ }^{16}$ recently described the possibility for a paracrine effect of LITA on the nearest endothelium of the anastomosed vessel.

A recent cornerstone paper by Kahn and colleagues ${ }^{17}$ showed lower graft patency at short-term follow-up after OPCABG compared with on-pump CABG. However, the long-term patency is affected critically by the genetically modulated atherosclerotic process, ${ }^{18}$ which is in a reverse relationship with the flow rate throughout the graft itself. ${ }^{19}$ On the other hand, the short-term patency critically depends on technical accuracy, which can be investigated by TTF. 3 However, our TTF analysis confirms our previous findings showing that perioperative patency is not influenced by the off-pump technique. Moreover, the reported higher GFR of the $\mathrm{Y}$-conduit is confirmed regardless the perfusion strategy.

Although the efficacy of IABP has been extensively demonstrated, the effects of IABP on CABG flow remain uncertain. ${ }^{20}$ In particular, Meyns and coworkers ${ }^{21}$ showed, in an animal model, that blood flow was improved in both ITA and venous conduits when IABP was placed in the ascending aorta, but not when placed in the descending aorta. Takami and Masumoto ${ }^{22}$ proved in humans that the degree of increase is greater in the in situ LITA supplying the LAD artery than in aorta-coronary grafts anastomosed to other coronary arteries. We confirm here that IABP can increase diastolic and mean CABG flow with no increase in mean systemic arterial pressure, ${ }^{3}$ either in the LITA or in the RA. These data could suggest that the augmented diastolic pressure, in association with the systolic unloading, is responsible for the increased flow with IABP. Although these data may also be related to the proximity of the IABP and the subclavian artery (proportionately greater augmented flow for composite compared with aorta-coronary RA grafts), certainly more studies are needed to further clarify these topics.

Despite our data conflict with those of Tsuchida, ${ }^{23} \mathrm{Ki}$ mura, ${ }^{24}$ and their associates, who noted that IABP was not associated with improved coronary flow distal to sites of ste- nosis, our results can be ascribed to the fact that normally functioning $\mathrm{CABG}$ would, by definition, circumvent mechanical obstructions to coronary flow caused by stenosis. Definitely more studies with pressure-volume loops are necessary to better address this topic, especially in experimental animal models.

These results could suggest the use of IABP for patients with arterial grafting with evidence of hypoperfusion syndrome. Mechanistically, these results also suggest that LITA can adapt quickly to accommodate large increases in flow, whereas the proximal aortic anastomosis of the RA may not be able to respond quantitatively to the same degree. Accordingly, our TTF findings support extending the indication for Y-grafts, beyond that of the generally accepted porcelain/severely diseased aorta. However, our results are consequential to our policy of a more liberal use of IABP and may not be in accordance with that of other surgeons in the methodology of the study and of our clinical and surgical practice.

It is not clear that similar results would occur in other clinical scenarios, such as during exercise or under pharmacologic stress. Intraoperative pharmacologic tests using either dobutamine or adenosine are widely established methods to evaluate graft function. However, the chronotropic response to dobutamine or the potential hypotension after adenosine administration can impair the hemodynamics of an ischemic patient. On the other hand, IABP helps to "stabilize", the hemodynamic status. Moreover, we have already demonstrated IABP as an alternative tool to investigate GFR. ${ }^{3,7}$ Moreover, the peculiar changes of TTF resulting in functioning and malfunctioning grafts with and without IABP support suggest TTF analysis during IABP assistance $1: 1$ as a useful adjunct to the clinical practice whenever an IABP is still in place.

We therefore conclude that baseline TTF results of single aorta-coronary RA CABGs are comparable with those of composite LITA-RA Y-grafts. However, IABP-induced GFR was more highly recruited in composite Y-conduits than in aorta-coronary CABG, regardless of the grafted territory and the perfusion strategy. In our opinion, TTF analysis should be routinely employed during coronary surgery as a satisfactory instrument for intraoperative graft surveillance. Moreover, the combination of IABP and TTF technology can help in early detection of malfunctioning RA grafts through demonstration of poor baseline TTF results and the absent recruitment of GFR.

A major limitation of the study is the absence of a systematic angiographic control in the 2 groups. Obviously, angiography is still the gold standard method to detect graft patency $^{25}$; however, TTF analysis has been introduced in the surgical armamentarium as an intraoperative diagnostic tool. Several reports comparing TTF and coronary angiography demonstrated that intraoperative TTF results correlate with angiography at short- and midterm follow-up. ${ }^{4,10,11}$ 
Certainly the intraoperative readings are affected by several intraoperative factors. Accordingly, we tried to standardize the intraoperative analysis also using each patient as his or her own "control" to minimize such bias. ${ }^{3}$

Another limitation of the study is the lack of a properly designed investigation to ascertain differences between TTF results among patients undergoing CABG on-pump versus off-pump. However, some reports confirmed that TTF is a valuable tool in determining coronary graft patency after $\mathrm{CABG}$ either with or without $\mathrm{CPB} .{ }^{10}$ Accordingly, analysis of the OPCABG subgroup further confirmed the results that we found among the whole patient population analyzed in the present study.

\section{References}

1. Verma S, Szmitko PE, Weisel RD, Bonneau D, Latter D, Errett L, et al. Should radial arteries be used routinely for coronary artery bypass grafting? Circulation. 2004;110:e40-6.

2. Buxton BF, Hayward PAR, Newcomb AE, Moten S, Seevanayagam S, Gordon I. Choice of conduits for coronary artery bypass grafting: craft or science? Eur $J$ Cardiothorac Surg. 2009;35:658-70.

3. Onorati F, Santarpino G, Rubino AS, Cristodoro L, Scalas C, Renzulli A. Intraoperative bypass graft flow in intra-aortic balloon pump-supported patients: differences in arterial and venous sequential conduits. J Thorac Cardiovasc Surg. 2009;138:54-61.

4. Di Giammarco G, Pano M, Cirmeni S, Pelini P, Vitolla G, Di Mauro M. Predictive value of intraoperative transit-time flow measurement for short-term graft patency in coronary surgery. J Thorac Cardiovasc Surg. 2006;132:466-7.

5. Wendler O, Hennen B, Markwirth T, Konig J, Tscholl D, Huang Q, et al. T graft with the right internal thoracic artery to left internal thoracic artery versus the left internal thoracic artery and radial artery: flow dynamics in the internal thoracic artery main stem. J Thorac Cardiovasc Surg. 1999;118: $841-8$.

6. Affleck DG, Barner HB, Bailey MS, Perry LA, Maniar H, Prasad SM, et al. Flow dynamics of the internal thoracic and radial artery T-graft. Ann Thorac Surg. 2004;78:1290-4.

7. Onorati F, Pezzo F, Comi MC, Impiombato B, Esposito A, Polistina M, et al. Radial artery graft function is not affected by age. J Thorac Cardiovasc Surg. 2007; 134:1112-20

8. Royse AG, Royse CF, Groves KL, Bus B, Yu G, App M. Blood flow in composite arterial grafts and effect of native coronary flow. Ann Thorac Surg. 1999;68: 1619-22.

9. Acar C, Jebara VA, Portoghese M, Beyssen B, Pagny JY, Grare P, et al. Revival of the radial artery for coronary artery bypass grafting. Ann Thorac Surg. 1992;54: 652-60.
10. Schmitz C, Ashraf O, Schiller W, Jürgen Preusse C, Esmailzadeh B, Likungu JA, et al. Transit time flow measurement in on-pump and off-pump coronary artery surgery. J Thorac Cardiovasc Surg. 2003;126:645-50.

11. D'Ancona G, Karamanoukian HL, Ricci M, Schmid S, Bergsland J, Salerno TA Graft revision after transit time flow measurement in off-pump coronary bypass grafting. Eur J Cardiothorac Surg. 2000;17:287-93.

12. Markwirth T, Hennen B, Scheller B, Schafers HJ, Wendler O. Flow wire measurements after complete arterial revascularization with T-grafts. Ann Thorac Surg. 2001;71:788-93

13. Desai ND, Naylor CD, Kiss A, Cohen EA, Feder-Elituv R, Miwa S, et al. Radial Artery Patency Study Investigators. Impact of patient and target-vessel characteristics on arterial and venous bypass graft patency: insight from a randomized trial. Circulation. 2007;115:684-91.

14. He G-W, Liu Z- G. Comparison of nitric oxide release and endothelium-derived hyperpolarizing factor-mediated hyperpolarization between human radial and internal mammary arteries. Circulation. 2001;104(suppl I):I344-9.

15. Chardigny C, Jebara VA, Acar C, Descombes JJ, Verbeuren TJ, Carpentier A et al. Vasoreactive of the radial artery comparison with the internal mammary artery and gastroepiploic arteries with implications for coronary artery surgery. Circulation. 1993;88(5 Pt 2):II115-27.

16. Tarr IF, Sasvari M, Tarr M, Racz R. Evidence of nitric oxide produced by the internal mammary artery graft in venous drainage of the recipient coronary artery. Ann Thorac Surg. 2005;80:1728-31.

17. Khan NE, De Souza A, Mister R, Flather M, Clague J, Davies S, et al. A randomized comparison of off-pump and on-pump multivessel coronary artery bypass surgery. N Engl J Med. 2004;350:21-8.

18. Cable DG, Caccitolo JA, Caplice N, O'Brien T, Simari RD, Daly RC, et al. The role of gene therapy for intimal hyperplasia of bypass grafts. Circulation. 1999; 100(19 Suppl):II392-6

19. Faulkner SL, Fisher RD, Conkle DM, Page DL, Bender HW Jr. Effect of blood flow rate on subendothelial proliferation in venous autografts used as arterial substitutes. Circulation. 1975;52(suppl. II):II163-72.

20. Yoshitani H, Akasaka T, Kaji S, Kawamoto T, Kume T, Neishi Y, et al. Effects of intraaortic balloon counterpulsation on coronary pressure in patients with stenotic coronary arteries. Am Heart J. 2007;154:725-31.

21. Meyns BP, Nishimura Y, Jashari R, Racz R, Leunens VH, Flameng WJ. Ascending versus descending aortic balloon pumping: organ and myocardial perfusion during ischemia. Ann Thorac Surg. 2000;70:1264-9.

22. Takami Y, Masumoto H. Effects of intra-aortic balloon pumping on graft flow in coronary surgery: an intraoperative transit-time flowmetric study. Ann Thorac Surg. 2008;86:823-7.

23. Tsuchida M, Yamato Y, Watanabe T, Ohzeki H, Hayashi J. Changes in graft flow pattern from the descending aorta due to intraaortic balloon pump. Ann Thorac Surg. 2000;70:981-2.

24. Kimura A, Toyota E, Lu S, Goto M, Yada T, Chiba Y, et al. Effects of intraaortic balloon pumping on septal arterial blood flow velocity waveform during severe left main coronary artery stenosis. J Am Coll Cardiol. 1996;27:810-6.

25. Glineur D, Hanet C, D'hoore W, Poncelet A, De Kerchove L, Etienne PY, et al. Causes of non-functioning right internal mammary used in a Y-graft configuration: insight from a 6-month systematic angiographic trial. Eur J Cardiothorac Surg. 2009;36:129-35. 
TABLE E1. Preoperative and intraoperative variables

\begin{tabular}{|c|c|c|c|}
\hline Variables & $\begin{array}{c}\text { Group A } \\
\text { (72 patients) }\end{array}$ & $\begin{array}{c}\text { Group B } \\
(42 \text { patients) }\end{array}$ & $P$ value \\
\hline Age & $67.5 \pm 6.6$ & $66.9 \pm 6.7$ & 679 \\
\hline Male sex & $66(91.7 \%)$ & $39(92.9 \%)$ & .563 \\
\hline Diabetes mellitus & $47(65.3 \%)$ & $25(59.5 \%)$ & .338 \\
\hline Hypertension & $58(80.6 \%)$ & $32(76.2 \%)$ & .373 \\
\hline COPD & $49(68.1 \%)$ & $29(69.0 \%)$ & .542 \\
\hline Dyslipidemia & $44(61.1 \%)$ & $26(61.9 \%)$ & .547 \\
\hline Acute MI $(<4$ wk $)$ & $36(50.0 \%)$ & $22(52.4 \%)$ & .480 \\
\hline Subacute MI & $22(30.6 \%)$ & $12(28.6 \%)$ & .499 \\
\hline LMSD & $19(26.4 \%)$ & $16(38.1 \%)$ & .137 \\
\hline $\mathrm{LVEF}<30 \%$ & $9(12.5 \%)$ & $8(19.0 \%)$ & .248 \\
\hline LVEF $30 \%-50 \%$ & $52(72.2 \%)$ & $27(64.3 \%)$ & .249 \\
\hline LVEF $>50 \%$ & $11(15.3 \%)$ & $7(16.7 \%)$ & .521 \\
\hline TIMI LAD & $0.7 \pm 0.6$ & $0.6 \pm 0.7$ & .484 \\
\hline TIMI CX & $0.6 \pm 0.5$ & $0.7 \pm 0.5$ & .387 \\
\hline TIMI RX & $0.9 \pm 0.7$ & $1.0 \pm 0.7$ & .496 \\
\hline No. CABG/patients & $3.2 \pm 0.5$ & $3.4 \pm 0.7$ & .089 \\
\hline OPCABG & $24(33.3 \%)$ & $15(35.7 \%)$ & .476 \\
\hline CPB CABG & $48(66.7 \%)$ & $27(64.3 \%)$ & .476 \\
\hline ACC time (min) & $49.2 \pm 5.7$ & $48.8 \pm 5.6$ & .829 \\
\hline CPB time (min) & $85.2 \pm 13.1$ & $90.8 \pm 14.7$ & .099 \\
\hline Total arterial CABG & $12(16.7 \%)$ & $12(28.6 \%)$ & .104 \\
\hline Associated mitral surgery & $22(30.6 \%)$ & $14(33.3 \%)$ & .458 \\
\hline $\begin{array}{l}\text { Associated aortic valve } \\
\text { surgery }\end{array}$ & $6(8.3 \%)$ & $5(11.9 \%)$ & .377 \\
\hline Asociated SVR & $7(9.7 \%)$ & $3(7.1 \%)$ & .460 \\
\hline \multicolumn{4}{|c|}{$\begin{array}{l}C O P D \text {, Chronic obstructive pulmonary disease; } M I \text {, myocardial infarction; } L M S D \text {, left } \\
\text { main stem disease; } L V E F \text {, left ventricular ejection fraction; } T I M I \text {, Thrombolysis In } \\
\text { Myocardial Infarction; } L A D \text {, left anterior descending; } C X \text {, circumflex artery; } R X \text {, right } \\
\text { coronary artery; } C A B G \text {, coronary artery bypass grafting; } O P C A B G \text {, off-pump surgery; } \\
C P B C A B G \text {, CABG on cardiopulmonary bypass; } A C C \text {, aortic crossclamping; } C P B \text {, } \\
\text { cardiopulmonary bypass; } S V R \text {, surgical ventricular restoration. }\end{array}$} \\
\hline
\end{tabular}

TABLE E2. Troponine leakage and doses of inotropes

\begin{tabular}{llll}
\hline & $\begin{array}{c}\text { Group A } \\
\text { (72 patients) }\end{array}$ & $\begin{array}{c}\text { Group B } \\
\mathbf{( 4 2} \text { patients) }\end{array}$ & $\boldsymbol{P}$ value \\
\hline Troponin I $(\mu \mathrm{g} / \mathrm{L})$ & & & \\
$\quad$ Preoperative & $0.32 \pm 0.20$ & $0.30 \pm 0.21$ & .696 \\
$\quad$ First day & $0.87 \pm 0.24$ & $0.94 \pm 0.34$ & .186 \\
$\quad$ Second day & $1.62 \pm 0.35$ & $1.55 \pm 0.36$ & .350 \\
Inotropic support, No. & & & \\
$\quad(\%)]$ & & & \\
$\quad$ Low dose & $60 / 72(83.3 \%)$ & $32 / 42(76.2 \%)$ & .244 \\
$\quad$ Medium dose & $11 / 72(15.3 \%)$ & $9 / 42(21.4 \%)$ & .279 \\
$\quad$ High dose & $1 / 72(1.4 \%)$ & $1 / 42(2.4 \%)$ & .603 \\
\hline
\end{tabular}

TABLE E3. TTF results of well-functioning RA CABG by surgical technique

\begin{tabular}{|c|c|c|c|c|}
\hline & IABP D/C & 1:1 IABP & $\boldsymbol{P} \dagger$ & $\boldsymbol{P}_{\ddagger}^{\ddagger}$ \\
\hline \multicolumn{5}{|l|}{ CPB-CABG } \\
\hline \multicolumn{5}{|l|}{$\begin{array}{l}\text { Maximum diastolic } \\
\text { flow }\end{array}$} \\
\hline Group A (46 patients) & $67.3 \pm 17.2$ & $86.4 \pm 24.8$ & .0001 & .0001 \\
\hline Group B (27 patients) & $68.2 \pm 10.5$ & $137.1 \pm 22.6$ & .0001 & \\
\hline$P^{*}$ & .677 & .0001 & & \\
\hline \multicolumn{5}{|l|}{ Mean flow } \\
\hline Group A (46 patients) & $35.9 \pm 11.9$ & $48.2 \pm 15.8$ & .0001 & .0001 \\
\hline Group B (27 patients) & $35.9 \pm 8.3$ & $71.7 \pm 17.2$ & .0001 & \\
\hline$P^{*}$ & .560 & .0001 & & \\
\hline \multicolumn{5}{|l|}{ Pulsatility index } \\
\hline Group A (46 patients) & $2.3 \pm 1.0$ & $3.1 \pm 0.8$ & .0001 & .952 \\
\hline Group B (27 patients) & $1.9 \pm 0.5$ & $3.5 \pm 0.6$ & .0001 & \\
\hline$P^{*}$ & .154 & .001 & & \\
\hline GFR & $1.3 \pm 0.2$ & $2.0 \pm 0.2$ & & .0001 \\
\hline \multicolumn{5}{|l|}{ OPCABG } \\
\hline \multicolumn{5}{|l|}{$\begin{array}{l}\text { Maximum diastolic } \\
\text { flow }\end{array}$} \\
\hline Group A (23 patients) & $69.2 \pm 16.5$ & $65.8 \pm 13.2$ & .0001 & .003 \\
\hline Group B (15 patients) & $87.4 \pm 26.3$ & $135.3 \pm 30.6$ & .0001 & \\
\hline$P^{*}$ & .230 & .0001 & & \\
\hline \multicolumn{5}{|l|}{ Mean flow } \\
\hline Group A (23 patients) & $35.8 \pm 8.5$ & $37.6 \pm 11.6$ & .0001 & .008 \\
\hline Group B (15 patients) & $50.3 \pm 14.1$ & $74.4 \pm 24.7$ & .0001 & \\
\hline$P^{*}$ & .842 & .0001 & & \\
\hline \multicolumn{5}{|l|}{ Pulsatility index } \\
\hline Group A (23 patients) & $2.2 \pm 1.1$ & $1.7 \pm 0.3$ & .0001 & .817 \\
\hline Group B (15 patients) & $2.8 \pm 0.9$ & $3.5 \pm 0.4$ & .0001 & \\
\hline$P^{*}$ & .243 & .0001 & & \\
\hline GFR & $1.4 \pm 0.2$ & $1.9 \pm 0.2$ & & .0001 \\
\hline
\end{tabular}

$T T F$, Transit-time flowmetry; $R A$, radial artery; $C A B G$, coronary artery bypass grafting; $I A B P$, intra-aortic balloon pumping; $D / C$, discontinued; $C P B$, cardiopulmonary bypass; $G F R$, graft flow reserve; $O P C A B G$, off-pump CABG. $* P$ value for the comparison of flows at baseline and during IABP $1: 1 ; \dagger P$ value for comparison of flows within groups; $\ddagger P$ value for comparison of flows between groups 
TABLE E4. TTF results of well-functioning RA CABG by grafted territory

\begin{tabular}{|c|c|c|c|c|}
\hline & IABP D/C & 1:1 IABP & $\boldsymbol{P} \dagger$ & $\boldsymbol{P} \ddagger$ \\
\hline \multicolumn{5}{|l|}{$\mathrm{RX}$} \\
\hline \multicolumn{5}{|l|}{$\begin{array}{l}\text { Maximum diastolic } \\
\text { flow }\end{array}$} \\
\hline Group A (29 patients) & $67.2 \pm 18.5$ & $86.1 \pm 27.1$ & .0001 & .0001 \\
\hline Group B (17 patients) & $68.4 \pm 11.4$ & $141.9 \pm 26.4$ & .0001 & \\
\hline$P^{*}$ & .555 & .0001 & & \\
\hline \multicolumn{5}{|l|}{ Mean flow } \\
\hline Group A (29 patients) & $33.6 \pm 10.6$ & $46.8 \pm 16.4$ & .0001 & .004 \\
\hline Group B (17 patients) & $35.0 \pm 9.0$ & $70.0 \pm 18.6$ & .0001 & \\
\hline$P^{*}$ & .812 & .0001 & & \\
\hline \multicolumn{5}{|l|}{ Pulsatility index } \\
\hline Group A (29 patients) & $2.4 \pm 1.3$ & $3.1 \pm 1.1$ & .0001 & .775 \\
\hline Group B (17 patients) & $1.8 \pm 0.4$ & $3.6 \pm 0.5$ & .0001 & \\
\hline$P^{*}$ & .127 & .0001 & & \\
\hline \multicolumn{5}{|l|}{ GFR } \\
\hline Group A (29 patients) & $1.4 \pm 0.2$ & & & .0001 \\
\hline Group B (17 patients) & $2.0 \pm 0.2$ & & & \\
\hline \multicolumn{5}{|l|}{$\mathrm{CX}$} \\
\hline \multicolumn{5}{|l|}{$\begin{array}{l}\text { Maximum diastolic } \\
\text { flow }\end{array}$} \\
\hline Group A (40 patients) & $68.6 \pm 15.8$ & $87.2 \pm 23.4$ & .0001 & .0001 \\
\hline Group B (25 patients) & $66.7 \pm 11.7$ & $132.7 \pm 24.6$ & .0001 & \\
\hline$P^{*}$ & .381 & .0001 & & \\
\hline \multicolumn{5}{|l|}{ Mean flow } \\
\hline Group A (40 patients) & $37.6 \pm 10.8$ & $50.5 \pm 14.3$ & .0001 & .001 \\
\hline Group B (25 patients) & $37.5 \pm 9.8$ & $74.6 \pm 20.9$ & .0001 & \\
\hline$P^{*}$ & .751 & .0001 & & \\
\hline \multicolumn{5}{|l|}{ Pulsatility index } \\
\hline Group A (40 patients) & $2.2 \pm 0.8$ & $2.9 \pm 0.6$ & .0001 & .531 \\
\hline Group B (25 patients) & $1.9 \pm 0.5$ & $3.5 \pm 0.6$ & .0001 & \\
\hline$P^{*}$ & .299 & .0001 & & \\
\hline \multicolumn{5}{|l|}{ GFR } \\
\hline Group A (40 patients) & $1.3 \pm 0.2$ & & .0001 & \\
\hline Group B (25 patients) & $1.9 \pm 0.2$ & & & \\
\hline
\end{tabular}

